\title{
Adapting Human Well-being Frameworks for Ecosystem Service Assessments across Diverse Landscapes
}

\author{
Amv Villamagna ${ }^{1}$ and Craig Giesecke ${ }^{2}$
}

\begin{abstract}
There is broad support for the notion that ecosystem services influence human well-being (HWB), however, the means to measure such an effect are elusive. Measures of HWB are commonly used within the fields of psychology, economics, and international development, but thus far have not been integrated fully into ecosystem service assessments. We examine the multidimensional nature of HWB and discuss the need for a robust framework that captures its complex relationship with ecosystem services. We review several well-known HWB indices and describe the adaptation of two frameworks - the Economist Intelligence Unit's Quality of Life Index and the Sustainable Livelihoods Framework - to evaluate county-level HWB within the Albemarle-Pamlico Basin (Virginia and North Carolina, USA) using a stakeholder-engaged approach. We present maps of HWB that illustrate the results of both frameworks, discuss the feedback from stakeholders that guided indicator and data selection, and examine the observed differences in HWB throughout the basin. We conclude with suggestions for enhancing the role of ecosystem services in HWB indices.
\end{abstract}

Key Words: Albemarle-Pamlico basin; ecosystem services; human well-being; quality of life

\section{INTRODUCTION}

The assessment of ecosystem services is a fast growing, farreaching area of applied conservation science (Perrings 2006). Ecosystem services are commonly defined as the benefits people receive from ecosystems (Daily et al. 1997, MA 2005) and these benefits are thought to contribute to human well-being (HWB) (Fig. $1 b$ of MA 2005). In their review of ecosystem services and HWB, Butler and Oluoch-Kosura (2006) highlight numerous examples of how ecosystem services provide essential benefits, without which the perpetuation of human societies and maintenance of an acceptable quality of life would be dubious. For example, coastal ecosystems, including wetlands and mangroves, provide regulating services that help mitigate hurricane impacts. Similarly, cultural services such as aesthetically pleasing landscapes, emotional connections to outdoor activities, and societal importance of natural environments positively impact human health and cultural cohesion. In a similar way, HWB, or lack thereof, can also influence the provision of ecosystem services as decisions may favor the increase of financial profit at the expense of natural capital (Butler and Oluoch-Kosura 2006, Diaz et al. 2006).

As ecosystem service research continues to grow in extent and complexity, however, the link between services and HWB remains complex and difficult to quantify. Monetary values are not available for many services and economic assessments often fail to capture the full array of nonmaterial values that contribute to HWB (Chan et al. 2012). Although it is easy to conceptualize the effect that ecosystem services have on HWB, the explicit links among individuals, communities, and provision of ecosystem services are not easy to measure and tend to vary across the environmental and socio-economic landscapes (Balmford and Bond 2005, Diaz et al. 2006, Keeler et al. 2012). Likewise, our inability to map the HWB benefits derived from ecosystem services prevents us from incorporating issues of social equity into land-use planning and conservation decisions (Wilson and Howarth 2002, Norman et al. 2012). To better understand these complex relationships, ecosystem service scientists should adopt a robust framework that captures the multidimensionality of
HWB, can detect differences over time and space, and examines how ecosystem services affect HWB across the spectrum from poverty to affluence. We identify and evaluate mappable indices of HWB. We propose that some indices can be used to evaluate HWB tradeoffs associated with landscape-level decisions that may affect ecosystem service provision.

\section{Measuring Human Well-being}

HWB is a multidimensional concept that is measured along a quality-of-life gradient that reflects the spatiotemporal variability of material (food, water, shelter) and nonmaterial needs (good health, social cohesion, security) (Butler and Oluoch-Kosura 2006, Petrosillo et al. 2013). Developing a multidimensional metric that can be used to measure changes in HWB in response to biophysical and socioeconomic changes that affect ecosystem service provision is needed, but challenging. The metric needs to be flexible so that it can be applied to diverse environmental and socio-economic landscapes where the balance of material and nonmaterial components of HWB varies substantially; however it must also be consistent enough to allow comparisons. For some scientists, the most accurate assessment of HWB can only come from surveys and interviews because HWB can be subjective (i.e., a personal reflection of basic human needs), even if measured using objective proxies (Petrosillo et al. 2013). For others, objective measures like income, literacy, and health status are more informative because they ignore the perspectives and beliefs of individuals and estimate HWB based on predetermined conditions that are uniformly measured and comparable across landscapes (Oswald and Wu 2010). Although the two approaches are quite different and provide different results, they need not be mutually exclusive (Sen 1999, Hagerty et al. 2001). Instead, objective HWB measures can be fine-tuned by incorporating subjective, survey-based weights to adjust the composite measure (e.g., Oswald and $\mathrm{Wu} 2010$ ).

\section{Past efforts}

The various compositions of HWB indices range from simple (e.g., national gross domestic product per capita, Appendix 1) to very complex (e.g., Federation of Canadian Municipalities, Appendix 1; Burrett 2009). Though each has been developed within a unique 
context and for a specific goal, comparing indices helps identify useful frameworks for conceptualizing HWB and provides a wealth of potential indicators for measurement and analysis.

\section{Composite Indices}

A HWB index that reflects the multidimensional nature of the human condition, including social, physical, psychological, or material dimensions is generally preferable to a single indicator metric (McGillivray and Noorbakhsh 2004). There is considerable difference among composite indices. Single-value composite measures provide easy reference for large comparative analyses, but are less helpful for understanding trade-offs and differences in the composition of HWB. Ideally, a composite index would provide an overall relative ranking that is interpretable on its own but also can be deconstructed to examine aforementioned trade-offs and explore relationships between well-being and physical and social environments across geographic and temporal scales. However, a composite index with too many indicators can become an unwieldy tool for which data may be difficult to collect, indicators may be redundant, and measuring such levels of detail may not be applicable in many situations. In contrast, simpler indices may rely too heavily on a small set of indicators that may not capture the full scale of HWB. The objective should be considered when choosing the number of indicators to include. A highly detailed, spatially-explicit index may be appropriate for informing policy makers at a local level whereas a simplistic, coarse scale serves to make general comparisons among countries. Ecosystem services assessments also vary along this spectrum; therefore having a HWB framework that can support the inclusion of additional indicators when needed without detracting from the power of the index is attractive. Hagerty and colleagues (2001) provide a list of fourteen criteria with which to evaluate indices of HWB in a public policy setting, many of which are equally important for evaluating the effect of ecosystem service tradeoffs. However, meeting all the criteria is challenging, particularly regarding subjective measurement of satisfaction, and eliciting strong ties between ecosystem service provision and HWB indicators is extremely difficult (Keeler et al. 2012). Nevertheless, natural capital is an essential contributor to life satisfaction (King et al. 2013) and is an important dimension in measuring wellbeing (Abdallah et al. 2008, Engelbrecht 2009, Knight and Rosa 2011).

To identify existing HWB frameworks and indicators that may help fill the quantitative gap between ecosystem services and HWB, we have evaluated several HWB indices that are common within the fields of international development and welfare economics. These included the United Nations Development Programme's 2010 Human Development Index, The Economist Intelligence Unit's Quality of Life (QoL) Index, the Index of Sustainable Economic Welfare, the Environmental Protection Agency's Human Well-being index, the Federation of Canadian Municipalities' Quality of Life Reporting System, and the Sustainable Livelihoods Framework (SLF). The indices were selected to represent a spectrum of methodologies used to measure HWB and that incorporate many of the characteristics deemed desirable in HWB research (Sen 1999, Hagerty et al. 2001, Camfield et al. 2009, King et al. 2013). We limit our in-depth discussion to the QoL and the SLF that were adapted to map HWB at the county-scale within the Albemarle-Pamlico watershed (Virginia and North Carolina, USA). We describe other relevant frameworks in Appendix 1. We also describe the process of adapting the QoL, selected by the authors prior to stakeholder meetings based on its multidimensionality, and SLF, adopted by authors following feedback from stakeholders based on its flexibility and representation of different forms of noneconomic capital, for use at the county-level. We describe the selection of appropriate data inputs and parameter weights for indicators based on stakeholder input and share our experiences in hopes of progressing toward a common HWB framework for ecosystem service studies.

\section{The Economist Intelligence Unit's Quality of Life Index}

The QoL developed by The Economist Intelligence Unit (2004) used international life satisfaction surveys to determine the multiple dimensions of well-being and their relative importance. The QoL's definition of well-being includes five social dimensions (political stability, family life, community life, political freedom, gender equality), two financial dimensions (material well-being, job security), and one dimension each for health and environment (climate and geography). With a total of nine indicators, the QoL is a relatively broad index well-suited for international comparisons.

\section{The Sustainable Livelihoods Framework}

The SLF was created in the late 1990s by the UK Department for International Development to link local well-being perspectives to policy to make management decisions in an international development context (Carney 2003). Although not developed as a HWB index, the SLF comprises five equally-weighted capital components and defines capital as the range of available assets that provide the building blocks for livelihoods and well-being (Farrington et al. 1999), including human, social, financial, physical, and natural capitals. Similar to Sen's capabilities approach (McGillivray and Noorbakhsh 2004), the SLF model proposes that individuals and communities combine types of capital and make trade-offs in allocating these resources to create or modify their livelihoods (Scoones 1998). Since inception, the SLF has been adapted to many contexts, including well-being measurement, program monitoring, and ecosystem service management (Carney 2003).

\section{METHODS}

On the basis of the review of HWB literature, we used stakeholder input to map HWB in the Albemarle-Pamlico basin, first using the QoL approach and second, after substantial feedback from stakeholders, with the SLF. We mapped and presented the results of HWB metrics to Albemarle-Pamlico basin stakeholders three times between 2010 and 2012 and used their feedback to revise indicator selection and remap. We describe the mapping of HWB indices, indicator and data selection, and how we responded to stakeholder feedback.

\section{Study Area: Albemarle-Pamlico Basin}

The Albemarle-Pamlico Basin (APB) stretches across Virginia and North Carolina (7770 hectares) and includes the watersheds for the Chowan, Roanoke, Tar-Pamlico, and Neuse Rivers. The APB is largely rural in character, with forestry and agricultural activities interspersed with natural areas. Densely populated areas are generally isolated along the Atlantic coast and near RaleighDurham, North Carolina. The livelihoods of people within this region are closely tied to ecosystems and natural resources with 
Table 1. Nine factors of The Economist Intelligence Unit's Quality of Life Index (2004) and factor weights applied to mapping quality of life in the Albemarle-Pamlico basin.

\begin{tabular}{|c|c|c|c|c|}
\hline \multirow[b]{2}{*}{ Quality of Life Factors } & \multirow[b]{2}{*}{ Indicators } & \multirow[b]{2}{*}{ Coefficient } & \multicolumn{2}{|c|}{ Factor weights } \\
\hline & & & $\begin{array}{l}\text { The } \\
\text { Economist } \\
\text { Survey }\end{array}$ & $\begin{array}{l}\text { Quality of } \\
\text { Life Index }\end{array}$ \\
\hline Material wellbeing & GDP per person, at purchasing power parity in $\$$. & 0.0003 & 11.5 & 18.8 \\
\hline Health & Life expectancy at birth, years. & 0.0448 & 15.0 & 19.0 \\
\hline Political stability and security & Political stability and security ratings. & -0.1052 & 14.3 & 11.3 \\
\hline Family life & $\begin{array}{l}\text { Divorce rate (per } 1000 \text { population), converted into index } \\
\text { of } 1 \text { (lowest divorce rates) to } 5 \text { (highest). }\end{array}$ & -0.1878 & 10.9 & 12.2 \\
\hline Community life & $\begin{array}{l}\text { Dummy variable taking value } 1 \text { if country has either high } \\
\text { rate of church attendance or trade-union membership; } \\
\text { zero otherwise. }\end{array}$ & 0.3865 & & \\
\hline Climate and geography & $\begin{array}{l}\text { Latitude, to distinguish between warmer and colder } \\
\text { climes. }\end{array}$ & -1.3534 & & \\
\hline Job security & Unemployment rate, $\%$ & -0.0217 & 11.9 & 7.7 \\
\hline Political freedom & $\begin{array}{l}\text { Average of indices of political and civil liberties. Scale of } \\
1 \text { (completely free) to } 7 \text { (unfree). }\end{array}$ & 0.1519 & 25.3 & 26.2 \\
\hline Gender equality & $\begin{array}{l}\text { Ratio of average male and female earnings, latest } \\
\text { available data. }\end{array}$ & 0.7423 & 11.1 & 4.7 \\
\hline
\end{tabular}

fishing, timber, and farming providing significant sources of income. Despite the abundance of natural resources and ecosystem services throughout the APB, severe and lasting poverty persists in some regions (McNaught and Nickens 2011). We chose to map HWB in the APB to complement concurrent efforts to quantify and map ecosystem services (A. Villamagna, B. Mogollon, and P. Angermeier unpublished manuscript).

\section{Applying the Quality of Life Index Approach}

In 2010, we chose the multidimensional QoL approach to map HWB in the Albemarle-Pamlico basin. We selected county-level data to quantify and map individual indicators and composite QoL scores using a) equal weights, b) weights derived from the Economist Intelligence Unit's survey, and c) weights derived from the QoL surveys (Table 1; also see Economist Intelligence Unit, 2004 for more detail). In March 2010, we presented the results to 13 NGO, state, and federal agency representatives who work and live in the Albemarle-Pamlico basin (Fig. 1). The response was uniform: the QoL Index did not reflect the values of the residents of the basin. Participants suggested that the index was biased towards urban areas because rural lifestyles were not adequately represented and that the index reflected European ideals that did not translate well to Virginia and North Carolina. Further comments and suggestions from participants are provided in Table 2.

In response to stakeholder input, we pursued the inclusion of additional indicators that would better reflect the wide range of values and ideals within North Carolina and Virginia. We found the QoL to be a weak framework to account for these largely human and social values. Rather than trying to introduce these values to the QoL index, we adopted the five-capital SLF approach that already accounts for human and social aspects of HWB. To better accommodate the range of HWB values highlighted by stakeholders, we applied weights to increase/ decrease the influence of capital and indicator values in the SLF based on stakeholder input. These weights were estimated based on stakeholder ranks. Allowing indicators to be weighted acknowledges that components are not perfectly substitutable and that well-being is subjective; the importance of its various components depends on regional and personal context.

\section{Adapting the Sustainable Livelihoods framework through stakeholder engagement}

We adopted the SLF for our follow-up analysis of HWB patterns throughout the APB because it reflected the multidimensionality of HWB and was designed to evaluate rural livelihoods. As described, the SLF comprises five capital asset indicators that contribute to overall HWB. We identified a short list of potential indicators (5-7) for each capital group that provided insight into the condition of that capital and for which data might be available at the county level). The list of potential indicators was developed from an extensive literature review (Table 3; also see Scoones 1998, Farrington et al. 1999, Economist Intelligence Unit 2004, DeFries and Pagiola 2005, Burrett 2009, Jordan et al. 2010, UNDP 2010) and formal and informal feedback from 2010 workshop participants.

In conjunction with ongoing ecosystem services research in the Albemarle-Pamlico basin, we reconvened in March 2011 to present a framework for evaluating ecosystem services and HWB together and to develop plausible futures for scenario analysis. Representative stakeholder groups for the 2011 workshop differed from the year before as they were selected to represent a wide array of conservation-oriented activity across the basin. The participating groups included small subbasin organizations, basin-wide organizations, federal and state agencies, and national-scale nongovernment organizations (NGOs). 
Fig. 1. The Economist's Intelligence Unit Quality of Life Index mapped for counties within the Albemarle Pamlico basin. The index was mapped with no factor weighting (left), weights according to The Economist surveys (middle), and weights according to the QoL surveys (right).
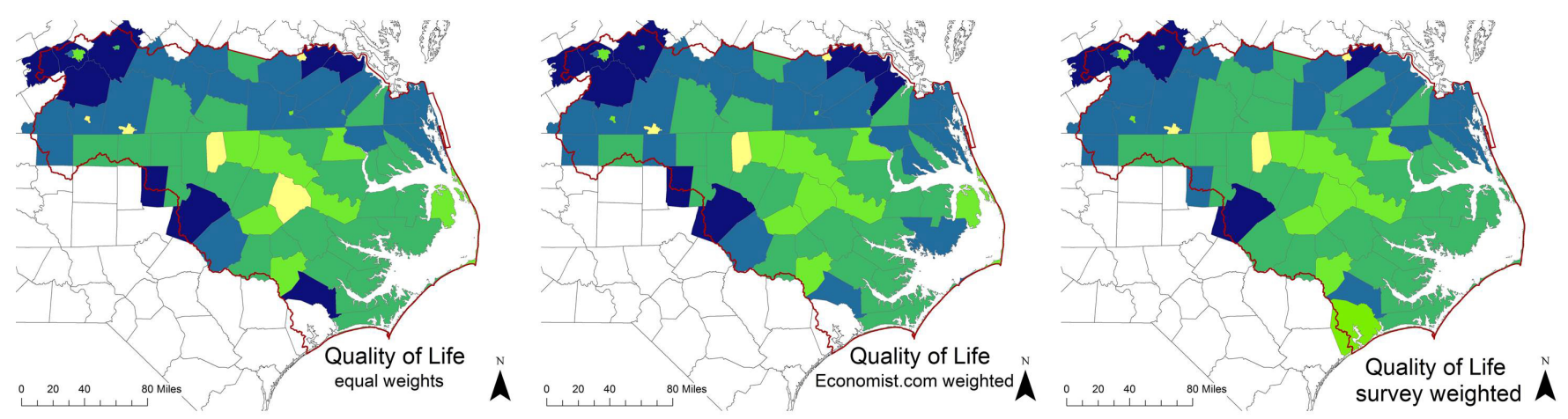

APBboundary

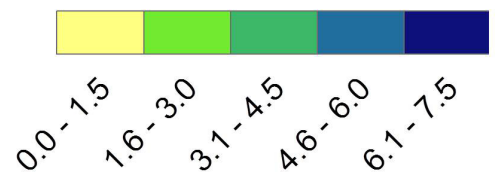

Coordinate System: NAD1983 UTM Zone 17N

During the workshop, we briefly introduced the SLF and explained how and why it would be used to map HWB across the Albemarle-Pamlico basin. To identify the indicators that best reflected HWB in the basin, workshop participants rated the importance to HWB of the five types of capital and the relative contribution of potential indicators to their respective capital asset. Respondents rated the types of capital on a 1-5 scale, with 5 being the most important to HWB. Indicators were also rated using the 1-5 scale, with 5 being a strong indicator for that component of well-being (Appendix 2).

We adapted the SLF basic framework to include partial weights for two indicators within each capital and for the capital asset's contribution to overall HWB (see Equation A3.1). The inclusion of two indicators added resolution to the assessment while maintaining interpretability. The equation applied reflects the contribution of each capital asset (financial, human, natural, physical, and social) to HWB and weights each capital indicator by dividing the mean (unscaled) rating by the sum of mean (unscaled) ratings (see Equation A3.2). This equation enabled us to assess the condition of each capital asset individually and collectively as a composite measure of HWB.

\section{Data collection}

We used the stakeholder ratings of potential HWB indicators as a starting point for data collection and, where possible, collected data for the top two rated indicators for each capital asset (Table 4). If data for an indicator were not available, equivalent data were substituted (e.g., 'percent of adults with excellent or good health status' for the 'number of healthy days per person'). When logical substitutes were not available, the team sought data for the indicator with the next highest rating (e.g., education attainment for social capital). Indicator data were derived in tabular and spatial (ArcMap shapefiles) form from a variety of sources (Table 4). Final indicators and their weights are highlighted in bold type in Table 4 and Appendix 4 provides a detailed account of mapping methods.

\section{Mapping county-level indicators}

A comparison of standardized county-level data for each indicator on a scale of $0-1$ (Equation A4.3) allowed the team to apply the aforementioned weighting equation (Equation A3.2) using the ranks assigned by workshop participants. The initial data tables were managed in Microsoft Excel and then joined to a county boundary shapefile in ArcMap 10.0 (ESRI 2010). The rescaled indicator values were also used to create radar plots for each county in the basin to compare the distribution of capital assets. Rescaled indicator values enabled comparison of capital asset condition and overall HWB across counties.

\section{Final stakeholder feedback}

In April 2012, stakeholders reconvened at a one-day meeting to present the SLF maps of HWB in the Albemarle-Pamlico basin. The participants were generally pleased with the five-capitals approach, but offered further comments and suggestions to enhance the accuracy of the index (Table 2). Where possible, we further adjusted the HWB index (e.g., included shoreline length) and recalculated county-level well-being. The team provided final HWB maps via an online data repository that has been used to share results and feedback since 2011.

\section{RESULTS}

The stakeholder approach to mapping HWB within the Albemarle-Pamlico basin enabled development of a measure that is flexible, transparent, and diverse. The SLF five-capital approach incorporated more indicators of noneconomic wellbeing than the adapted QoL and it allowed for the inclusion of indicators that reflect a wider range of sociocultural values. By mapping the individual measures, composite capitals, and composite HWB measures the research team could examine geographic patterns throughout the basin and examine these patterns in terms of the individual indicators used. Maps of equally-weighted capital (Fig. 2), stakeholder-weighted capital (Fig. 3), and radar charts (Fig. 4) helped us highlight interesting geographic patterns in individual HWB measures and composite 
Table 2. Stakeholder evaluation and feedback regarding the application of The Economist Intelligence Unit's Quality of Life (QoL) and Sustainable Livelihoods approaches to characterizing human well-being in the Albemarle-Pamlico basin. Comments were not provided for all QoL indicators and some comments were not directed at any given indicator. We have attempted to classify them according to the initial constructs of the QoL.

Stakeholder comments and suggestions

The Economist Intelligence Unit's Quality of Life Index Indicators

Health

Material well-being

Include health care availability (\# hospitals or proximity to hospitals) and incidence of anxiety.

Climate and

Relied too heavily on measures of income and not enough on sociocultural values related to the economy (e.g., trans-generational land ownership).

geography

Community life

Surrounding environment would be more informative than latitude, which varied little.

Job security

Include community activity (e.g., park use), not just church attendance.

Include frequency and severity of economic transitions and persistence of traditional (non-monetary) income.

Gender equality

Include high school graduation rates, not just higher education.

General comments

Some participants suggested comparing project QoL maps based on the indicators listed in Table 1 with another framework that might better reflect the interests and values of residents in the Albemarle-

Pamlico basin.

Sustainable Livelihoods Framework Capital Assets

Financial

The measure for income should be "disposable income" available via census data.

The employment measure from the census doesn't accurately represent the total number of people unemployed (no alternative provided).

Human Quality of diet and access to "grocery store" food (the concept of a "food desert"), combined with alternatives such as farmers' markets and wild food, should be used as metrics.

Natural

The open space measure holds a strong bias to rural areas.

Proximity of water indicator should include estuaries and marine areas, as these are important for the coastal region.

Physical Access to healthcare as a measure - via numbers of hospitals or doctors per 1000 people. Medical insurance coverage should also be taken into consideration in this metric.

Replace absolute cost of utilities and housing with the percentage of income to relate back to disposable income.

Social

Recreational opportunities that bring people together are good measures; include city parks and playgrounds.

Where possible, include participation in community groups (not very well documented in rural, impoverished areas).

Educational attainment by the census may not include people under the age of 25 . Therefore, high

school or college graduation may be a better indicator. Alternatively, some measure of retention after graduation may be important.

HWB and illustrate the utility of the HWB (discussed in next section).

\section{Geographic trends}

By examining maps of equally-weighted (Fig. 2a-e) and stakeholder-weighted indicators (Fig. 3a-e), a clear pattern among the financial, human, and natural capitals emerges within North Carolina counties south of Falls Lake, the Roanoke River reservoir located near Roanoke Rapids. Less water downstream of dam and the prevalence of agriculture in these counties contribute to this region having less natural capital than adjacent counties. These counties also share relatively low household income, lower health quality, and a shorter life expectancy for males when compared with other counties in the AlbemarlePamlico basin. An examination of spatial patterns among the capitals contributing to HWB shows that near uniformity of social capacity did not drive HWB for most counties, except perhaps in Wake County, NC, where all capitals (except physical capital) are greater than the neighbors.

Overall, HWB is heterogeneous throughout the AlbemarlePamlico basin. There is generally high HWB in up-basin counties (e.g., Roanoke, Montgomery, Franklin) with a substantial decrease among lower Roanoke River counties. Most cities have a lower HWB score than their surrounding counties. There is little difference between capital maps based on equally-weighted and stakeholder-weighted indicators (Fig. 2 and 3), due to nearly equal stakeholder rating of capital assets and indicator. 
Table 3. Capital components of the Sustainable Livelihoods Framework and potential indicators presented to stakeholders in AlbemarlePamlico watershed (North Carolina and Virginia, USA).

\begin{tabular}{|c|c|}
\hline Capital & Potential indicators \\
\hline \multirow[t]{6}{*}{ Human capital } & Life expectancy (DeFries and Pagiola 2005; UNDP 2010; The Economist 2004) \\
\hline & Infant mortality (DeFries and Pagiola 2005; Burrett 2009) \\
\hline & Satisfaction or happiness (Jordan et al. 2010) \\
\hline & Commuting time or distance (Burrett 2009) \\
\hline & Number of healthy days per person \\
\hline & Cancer rates/diabetes/chronic heart disease \\
\hline \multirow[t]{6}{*}{ Social capital } & Recreation values (DeFries and Pagiola 2005; Burrett 2009) \\
\hline & Number of and participation in religious or social groups (Burrett 2009) \\
\hline & Civic involvement (voting, meetings) (Burrett 2009) \\
\hline & Education attainment (Burrett 2009; DeFries and Pagiola 2005; UNDP 2010) \\
\hline & Divorce rate (The Economist 2004) \\
\hline & Access to occupational tools and opportunities \\
\hline \multirow[t]{6}{*}{ Financial capital } & Income (Burrett 2009; DeFries and Pagiola 2005; The Economist 2004; UNDP 2010) \\
\hline & Consumption (DeFries and Pagiola 2005) \\
\hline & Employment (Burrett 2009; The Economist 2004) \\
\hline & Cost of living \\
\hline & Investment in local business \\
\hline & Access to credit \\
\hline \multirow[t]{6}{*}{ Physical capital } & Value of personal physical assets (DeFries and Pagiola 2005) \\
\hline & Access to hospital and health care facilities (Burrett 2009) \\
\hline & Affordable housing (Burrett 2009) \\
\hline & Public transportation (Burrett 2009) \\
\hline & Infrastructure (roads, transportation) \\
\hline & Affordable electricity \\
\hline \multirow[t]{6}{*}{ Natural capital } & Days inconvenienced by drought or flood \\
\hline & Access to green space or open land \\
\hline & Access to rivers, lakes, or seashore \\
\hline & Forest cover \\
\hline & Abundance of fish and wildlife \\
\hline & Conversion of land to impervious surface \\
\hline
\end{tabular}

\section{County comparisons}

Values of the five capital profiles were plotted using a radar chart where each capital has an axis that ranges $0-1$ based on rescaling of raw values. We compared counties on the basis of similar HWB composite measures but different capital profiles (as illustrated in Fig. 4), variability in HWB measures among neighboring counties, and to examine differences in headwater compared with coastal counties.

Geographically, Carteret and Bedford counties are located on opposite ends of the watershed (Fig. 4a). These two counties share a very similar HWB score, yet the capitals that contribute to HWB differ greatly. Social capital, specifically percent recreation area, was substantially greater in Carteret county. In contrast, natural, human, and financial capitals were slightly higher in Bedford county near the top of the watershed.

Based on the proximity of Campbell, Pittsylvania, and Halifax counties to each other (located in the upper Albemarle-Pamlico basin), similar HWB measures might be expected; however HWB scores vary noticeably among these neighbors (Fig. 4b). The counties are practically equal in natural, physical, and social capital but differences in financial (employment 94\%, 92\%, and $87 \%$, respectively) and human capital drive the observed differences in HWB among counties. Similarly, Pitt and Edgecombe counties are neighboring counties in North Carolina with substantially different composite HWB scores (Fig. 4c). The two counties share roughly equal physical and natural capital, but vary greatly in financial, human, and social capital. Pitt has higher education attainment (29\% compared with $10 \%)$, employment (90.5\% compared with $84 \%$ ), and male life expectancy ( 72.9 years compared with $68.9 \mathrm{yrs}$ ).

We evaluated the relationship of HWB among three counties along an upstream-downstream continuum within the Neuse River basin and three within the Roanoke River basin. In the Neuse basin, Wake County is upstream of Johnston and Wayne counties and there are noticeable differences between asset portfolios with a general decreasing trend in downstream counties. Johnston and Wayne counties have lower natural, financial, human, and social capital values than Wake County. Only physical capital is lower in Wake than downstream neighbors, which can be attributed to high electricity costs and low property ownership (Fig. 4d). Along the Roanoke River (Fig. 4e), there is substantial variability in HWB, including a decline from Roanoke County (0.89) downstream to Franklin County (0.54), and further down to Brunswick County (0.36). These 
Table 4. Participants rated the importance of capitals to their overall well-being and potential indicators to their respective capital asset on a scale of 1-5, with 5 suggesting the strongest contribution to well-being. Each capital and indicator was ranked independently (i. e., more than one capital or indicator could share a rating) and averaged for all participants $(\mathrm{n}=12)$. Indicators included in this assessment are noted in bold.

\begin{tabular}{|c|c|c|}
\hline Capital asset and indicator & Data Sources & $\begin{array}{l}\text { Mean sd } \\
\text { rating }\end{array}$ \\
\hline
\end{tabular}

Human capital: The collection of knowledge, skills, and ability to contribute to society (e.g., education, health, etc.)

Life expectancy

Number of healthy days/person

$3.67 \quad 1.16$

Infant mortality

Life expectancy (IHME 2011)

$4.00 \quad 0.74$

Cancer rates/diabetes/chronic heart disease

$\%$ adults with excellent or good health status (Geographic Research Inc. ${ }^{\dagger}$ ) $\quad \mathbf{4 . 0 0} \quad \mathbf{0 . 9 5}$

Average commute time

$3.67 \quad 1.23$

$3.17 \quad 0.72$

$2.33 \quad 0.98$

Financial capital: Financial assets (e.g., money, stocks, etc.) that can be used to purchase physical assets $\quad \mathbf{3 . 5 8} \quad \mathbf{0 . 7 9}$

$\begin{array}{ll}\text { Employment } & \text { Employment (Geographic Research Inc. }{ }^{*} \text { ) } \\ \text { Income } & \text { Income: median household income (Geograt }\end{array}$

Income: median household income (Geographic Research Inc. $\left.{ }^{\S}\right)$

$3.92 \quad 1.00$

Cost of living

Investment in local businesses

$3.58 \quad 1.16$

Consumption

$2.92 \quad 0.90$

Access to credit

$\begin{array}{ll}2.75 & 0.97\end{array}$

$2.58 \quad 0.90$

Physical capital: Manufactured, nonhuman assets. Excludes raw materials (e.g., house, boat, car)

$3.08 \quad 1.38$

Access to hospital and health care facilities

Affordable housing

Affordable housing: percent households owning primary residence

$\begin{array}{ll}4.08 & 0.67\end{array}$

Affordable electricity

(Geographic Research Inc.')

Affordable electricity: average household monthly electricity bill (inverse)

3.921 .08

Value of personal physical assets (Geographic Research Inc. .)

3.920 .90

Health insurance coverage

$3.25 \quad 1.29$

Infrastructure (roads per capita)

$3.17 \quad 0.83$

Public transportation options

Social capital: Social relations and networks that provide benefits; can include formal and informal groups.

social groups

Access to occupational tools

Education attainment

Education attainment: percent of adults with undergraduate or graduate

$3.18 \quad 0.75$

Civic involvement (voting, meetings) degree (Geographic Research Inc. ${ }^{\#}$ )

Participation in traditional industries/

Natural capital: Stock of natural ecosystems that yields a flow of ecosystem goods or services (e.g., trees, wetlands,

Forest cover 
Fig. 2. Capital asset conditions equally-weighted. Top (left to right): Financial, Human, Natural; Bottom (left to right): Physical, Social, and the composite measure of HWB based on equally weighted capitals and indicators.
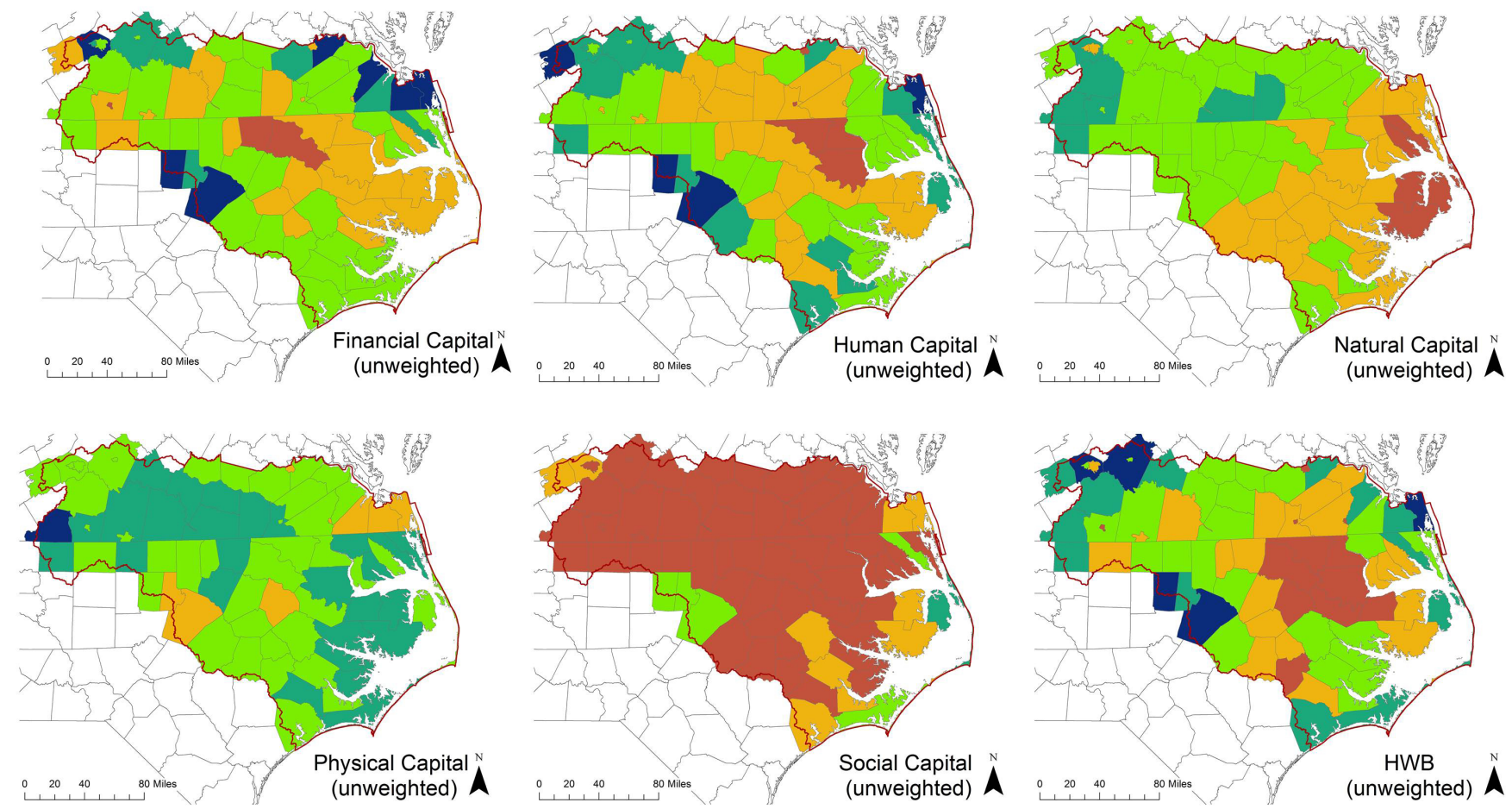

APBboundary

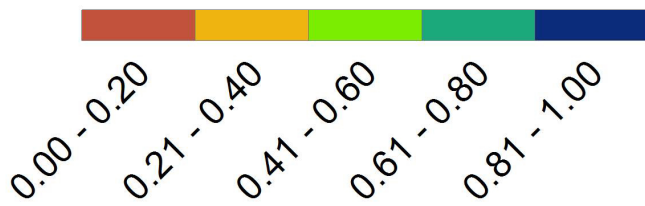

Coordinate System: NAD1983 UTM Zone 17N

counties largely differ with respect to financial (e.g., employment was equal to $94 \%, 90 \%$, and $88 \%$ for Roanoke, Franklin and Brunswick counties), human capital (e.g., male life expectancy 76, 74 , and 69.9 yrs), and social capital (e.g., $31 \%, 17 \%$, and $13 \%$ of adults hold undergraduate or graduate degrees, respectively.

\section{DISCUSSION}

Although HWB indices are most commonly used in the fields of psychology, international development, and economics, the notion of quantifying HWB has become increasingly important to the conservation sciences as ecosystem services march into the spotlight. Enhancing our collective ability to measure, map, and compare HWB across space and time is of increasing importance as more people look to HWB indices to measure human condition and progress (UNDP 2010). We applied our adapted index to measure HWB in a largely rural setting in the United States, but the index could be easily modified for more or less rural areas outside the U.S.
We reviewed several indices of HWB and described the adaptation of two well-recognized approaches. Although there was substantial progress on the quantification and mapping of $\mathrm{HWB}$, there is much to understand about how ecosystem services contribute to HWB and vice versa (Keeler et al. 2012). Most important is how changes in ecosystem services affect specific aspects of HWB and how to quantify these relationships. Some of the effects will be obvious and direct (e.g., the relationship between human health and water quality), whereas many others will be indirect (e.g., the relationship between education attainment and water quality). Users of HWB indices for ecosystem services assessments should be cognizant of secondary and tertiary impacts of ecosystem services change and include them in their models.

\section{Trade-offs: frameworks and indicators}

When choosing a HWB index there are many assumptions and trade-offs to consider. This research relied on a combination of literature review and stakeholder input to select indicators, data 
Fig. 3. Capital asset conditions weighted by stakeholder participating ratings. Top (left to right): Financial, Human, Natural; Bottom (left to right): Physical, Social, and the weighted composite measure of HWB using Equation 1.
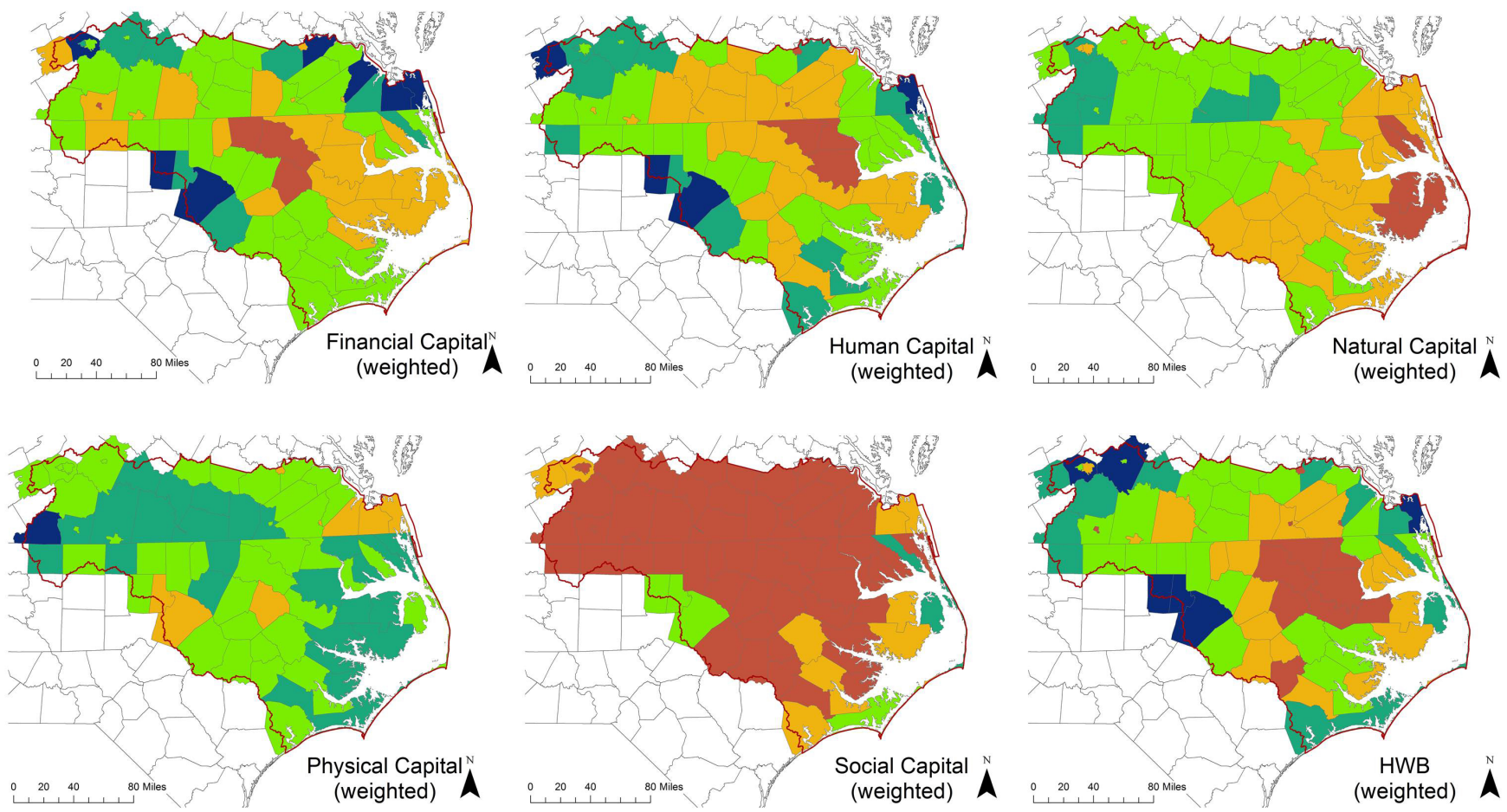

APBboundary

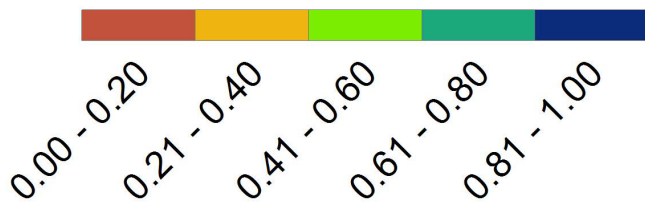

Coordinate System: NAD1983 UTM Zone 17N

sources, and indicator weights. We consider the implications of our choices and potential alternatives for future assessments.

Weighting interbasin variability

By choosing to apply the QoL Index and the SLF to map HWB in the Albemarle-Pamlico basin we assumed that the indicators selected were the best for the entire region. Given the large geographic extent and land use heterogeneity of the AlbemarlePamlico basin, this assumption may have been false for some indicators. This point was first made during the 2010 meeting when the QoL was rejected for its bias towards urban lifestyles and the concern resurfaced when participants at the 2012 meeting asked to add "proximity to shoreline" to complement "proximity to lakes and rivers" as subindicators of natural capital. Daw et al. (2011) also emphasizes the need to disaggregate HWB measures to ensure a clearer view of ecosystem services "winners" and "losers".
To adapt the SLF for our purposes, we weighted the capital assets and the individual indicators of each, but these weights were based on the average ranks for the entire Albemarle-Pamlico basin. Although this enabled comparison of counties across the entire basin based on a single framework, it may not reflect differences in individual needs, preferences, or access to ecosystem services (Daw et al. 2011). To account for intrabasin variability, future HWB assessments could estimate weights for a specific geographic area or, perhaps with greater difficulty, a group of people. The latter approach may provide a more realistic snapshot of perceived HWB, but in doing so trade the ability to compare all counties using the same objective measures. In reflection, expanding the SLF survey efforts to include a wider variety of Albemarle-Pamlico basin residents would help determine whether perceived importance of HWB capital assets and indicators varied by geography. In future assessments, intrabasin variability could be accounted for by applying weights stratified by county. 
Fig. 4. Five capital assets contributing to composite HWB measures compared across counties in the Albemarle-Pamlico basin. Values for each capital asset range from 0 to 1. Composite HWB values also range from 0 to 1 and are provided in legend. Top (left to right): Carteret and Bedford counties; Halifax, Pittsylvania, and Campbell counties; Pitt and Edgecombe counties; Bottom (left to right): Johnston, Wake, and Wayne counties; Franklin, Roanoke, and Brunswick counties.

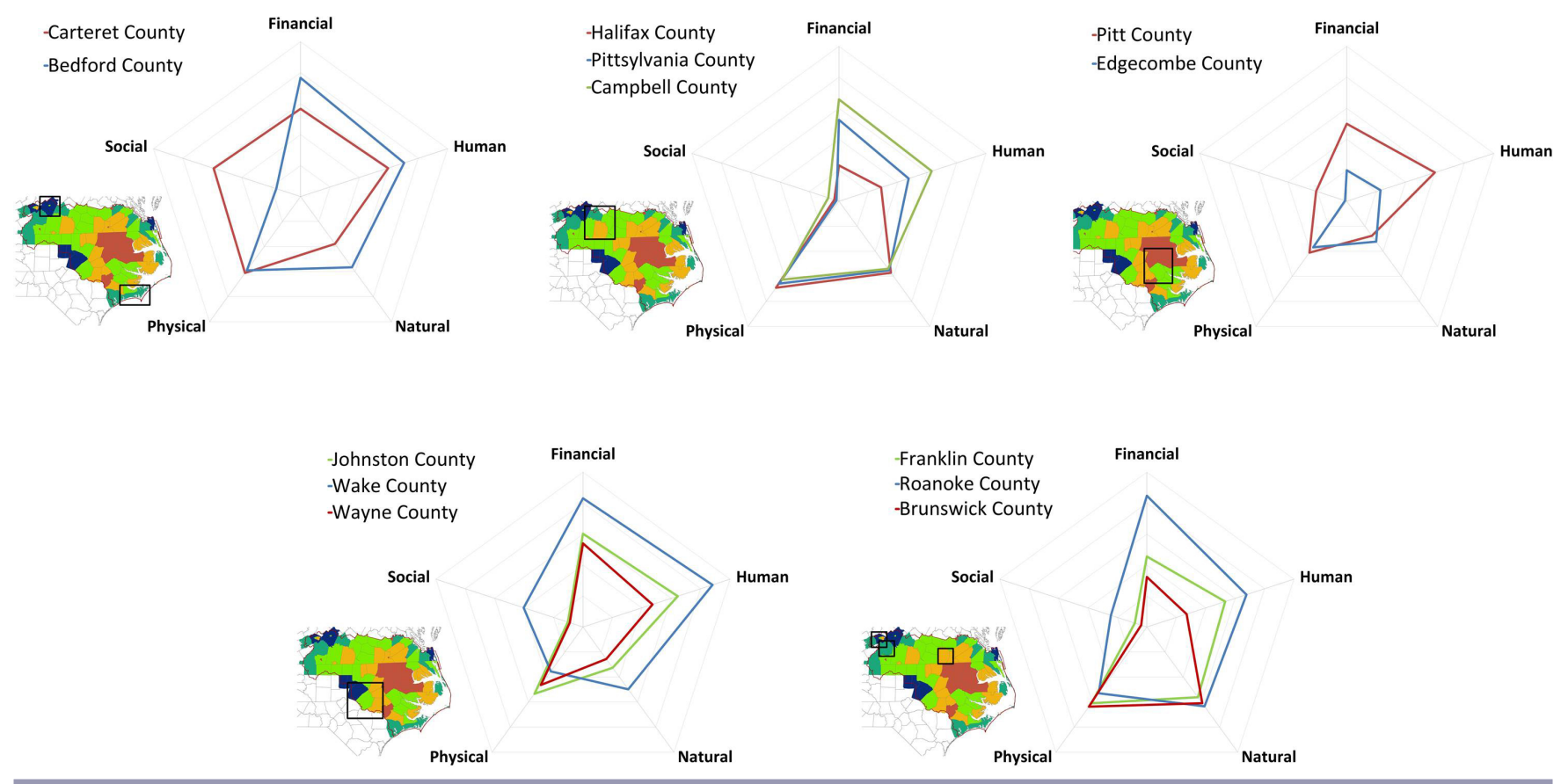

\section{Data constraints}

Despite efforts to build a comprehensive HWB index that performs well across a variety of landscapes and societies, researchers are ultimately limited by data availability. Collecting primary data is expensive and time consuming; thus, the only viable option for ecosystem service studies is to adopt an approach that can incorporate easily accessible data that cover the entire study area and are recent enough to support the objectives. This process shows that pure social metrics are hard to come by, whereas economic and health-related indicators are much easier to acquire, and most natural capital indicators can be drawn from remotely sensed datasets. Social measures like participation in community groups or activities, civic engagement, and overall social cohesion are extremely difficult to find. Likewise, it was challenging to include all forms of recreation. Fishing and hunting licenses were obtainable, but records on more passive forms of recreation (e.g., hiking) were not. Therefore, we included the sum of public use areas as a proxy for recreation, but recognize that outdoor recreation is just one avenue for social interaction. Other forms of recreation not accounted for may include participation in community recreation programs, playgrounds, and other areas where people may come together. We suspect that social capital data would be easier to collect for smaller-scale studies and therefore encourage future users of the SLF approach to include these more specific measures.

\section{CONCLUSIONS}

The study of ecosystem services and their contributions to HWB is growing and in need of a comprehensive framework for evaluating changes in HWB in space and time. Considering ecosystem services trade-offs in the context of well-being, rather than monetary values, would provide a better measure to help guide land use and management decisions (Chan et al. 2012). Adopting a framework that combines the ease of a single-score metric with a multidimensional portfolio of capital assets is an important first step. The SLF provides a strong foundation for HWB assessments, as it comprises five important dimensions that reflect the most commonly cited aspects of HWB, but also has flexibility needed for a single framework to be applied to ecosystem service studies worldwide. It can accommodate measures of basic human needs (e.g., access to clean water and food) or measures that reflect the differences in QoL in more affluent areas, like the Albemarle-Pamlico basin and much of the developed world.

We strongly recommend engaging stakeholders in HWB mapping as it provides an opportunity to calibrate the framework to reflect the most important perceived aspects of HWB. King et al. (2013) highlights the importance of a participatory approach and including stakeholder groups to gain a representative understanding of the study area and what contributes to HWB there. While a workshop to gather information from participants was used, a survey approach, where feasible, would be an improvement in which life satisfaction could be evaluated simultaneously and compared to the objective measures. Overall, this study provides a strong first step towards evaluating HWB, however the next step is to evaluate and adapt indicator selection to maximize the relevance for ecosystem service assessments. We 
suggest engaging stakeholders to develop specific relationships between important ecosystem services and HWB. For example, a decrease in the ecological service of water quality regulation will directly decrease human, natural, and social capital, while potentially stimulating an increase in physical capital (e.g., water treatment plants) and decreasing financial capital (e.g., per capita cost of water). In conclusion, this study provides a review and framework that we hope will help other natural and social scientists employ HWB measures in their investigations of ecosystem services.

\section{Responses to this article can be read online at: http://www.ecologyandsociety.org/issues/responses. php/6173}

\section{Acknowledgments:}

This work was funded by the U.S. Geological Survey's National Aquatic Gap Analysis Program. We would like to acknowledge P. Angermeier, E. Bennett, and B. Mogollon for their participation in the assessment of ecosystem services in the Albemarle-Pamlico basin and for their input and feedback on the development of the human well-being framework. A special thanks to $G$. Chan and $L$. Herzig for data collection and mapping efforts, and to L. Zseleczky for preliminary literature review. We thank $A$. Chmil, D. Inouye, A. Sunderman, and 3 anonymous reviewers for their comments and suggestions on earlier drafts.

\section{LITERATURE CITED}

Abdallah, S., S. Thompson, and N. Marks. 2008. Estimating worldwide life satisfaction. Ecological Economics 65(1):35-47.

Balmford, A. and W. Bond. 2005. Trends in the state of nature and implications for human well-being. Ecology Letters 8 (11):1218-1234. http://dx.doi.org/10.1111/j.1461-0248.2005.00814. $\underline{x}$

Burrett, J. 2009. Measuring quality of life in Canadian municipalities. Pages 155-164 in J. Sirgy, R. Phillips, and D. Rahtz, editors. Community quality-of-life indicators: best cases III. Volume 1. Springer Netherlands, Heidelberg, Germany. http://dx. doi.org/10.1007/978-90-481-2257-8_7

Butler, C. D., and W. Oluoch-Kosura. 2006. Linking future ecosystem services and future human well-being. Ecology and Society 11(1):30. [online] URL: http://www.ecologyandsociety. org/vol11/iss1/art30/

Carney, D. 2003. Sustainable livelihoods approaches: progress and possibilities for change. Department for International Development, London, England.

Camfield, L., G. Crivello, and M. Woodhead. 2009. Wellbeing research in developing countries: reviewing the role of qualitative methods. Social Indicators Research 90(1):5-31. http://dx.doi. org/10.1007/s11205-008-9310-Z

Chan, K. M. A., A. D. Guerry, P. Balvanera, S. Klain, T. Satterfield, X. Basurto, A. Bostrom, R. Chuenpagdee, R. Gould, B. S. Halpern, N. Hannahs, J. Levine, B. Norton, M. Ruckelshaus,
R. Russell, J. Tam, and U. Woodside. 2012. Where are cultural and social in ecosystem services? A framework for constructive engagement. BioScience 62(8):744-756. http://dx.doi.org/10.1525/ bio.2012.62.8.7

Costanza, R., and H. Daly. 1992. Natural capital and sustainable development. Conservation Biology 6(1):37-46. http://dx.doi. org/10.1046/j.1523-1739.1992.610037.x

Daily, G. C., S. Alexander, P. Ehrlich, L. Goulder, J. Lubchenco, P. Matson, H. Mooney, S. Postel, S. H. Schneider, D. Tilman, and G. M. Woodwell. 1997. Ecosystem services: benefits supplied to human societies by natural ecosystems. Issues in Ecology 2:2-16.

Daly, H. 2002. Reconciling the economics of social equity and environmental sustainability. Population and Environment 24 (1):47-53.

Dasgupta, P., and M. Weale. 1992. On measuring the quality of life. World Development 20(1):119-131. http://dx. doi. org/10.1016/0305-750X(92)90141-H

Daw, T., K. Brown, S. Rosendo, and R. Pomeroy. 2011. Applying the ecosystem services concept to poverty alleviation: the need to disaggregate human well-being. Environmental Conservation 38 (4):370-379. http://dx.doi.org/10.1017/S0376892911000506

DeFries, R., and S. Pagiola. 2005. Analytical approaches for assessing ecosystem condition and human well-being. Pages 37-71 in R. Hassan, R. Scholes, N. Ash, editors. Ecosystems and human well-being: current state and trends, volume 1. Island Press, Washington, D.C., USA.

Economist Intelligence Unit. 2004. The economist intelligence unit's quality-of-life index. The World in 2005. [online] URL: http://www.economist.com/media/pdf/QUALITY OF LIFE.pdf

Engelbrecht, H.-J. 2009. Natural capital, subjective well-being, and the new welfare economics of sustainability: some evidence from cross-country regressions. Ecological Economics 69 (2):380-388. http://dx.doi.org/10.1016/j.ecolecon.2009.08.011

ESRI. 2010. ArcGIS Desktop: Release 10.0. Redlands, CA: Environmental Systems Research Institute.

Farrington, J., D. Carney, C. Ashley, and C. Turton. 1999. Sustainable livelihoods in practice: early applications of concepts in rural areas. ODI Natural Resource Perspectives 42:1-10.

Hagerty, M., R. Cummins, A. Ferriss, K. Land, A. Michalos, M. Peterson, J. Sirgy, and J. Vogel. 2001. Quality of life indexes for national policy: review and agenda for research. Social Indicators Research 55(1):1-96. http://dx.doi.org/10.1177/075910630107100104

Institute for Health Metrics and Evaluation (IHME). 2011. Life Expectancies in US Counties, 2011. [online] URL: http://www. healthmetricsandevaluation.org/news-events/news-release/life-expectancyin-us-counties-2011

Jordan, S., W. Benson, M. Russell, J. Summers, L. Smith, D. Yoskowitz, and S. Hayes. 2010. Accounting for natural resources and environmental sustainability: linking ecosystem services to human well-being. Environmental Science and Technology 44 (5):1530-1536. http://dx.doi.org/10.1021/es902597u

Keeler, B. L., S. Polasky, K. A. Brauman, K. A. Johnson, J. C. Finlay, A. O’Neille, K. Kovacsf, and B. Dalzellg. 2012. Linking 
water quality and well-being for improved assessment and valuation of ecosystem services. Proceedings of the National Academy of Sciences of the United States of America 109 (45):18619-18624. http://dx.doi.org/10.1073/pnas.1215991109

King, M. F., V. F. Renó, and E. M. L. M. Novo. 2013. The concept, dimensions and methods of assessment of human well-being within a socioecological context: a literature review. Social Indicators Research. [online] URL: http://link.springer.com/ article/10.1007/s11205-013-0320-0 http://dx.doi.org/10.1007/ $\underline{\mathrm{s} 11205-013-0320-0}$

Klugman, J., F. Rodríguez, H. Choi. 2011. The HDI 2010: new controversies, old critiques. Journal of Economic Inequality 9 (2):249-288. http://dx.doi.org/10.1007/s10888-011-9178-Z

Knight, K. W., and E. Rosa. 2011. The environmental efficiency of well-being: a cross-national analysis. Social Science Research 40(3):931-949. http://dx.doi.org/10.1016/j.ssresearch.2010.11.002

Millennium Ecosystem Assessment (MA). 2005. Ecosystems and human well-being: synthesis. Island Press, Washington, D.C., USA.

McNaught, D. and T.E. Nickens. 2011. Horizon 2100: Aggressive Conservation for North Carolina's future. North Carolina Environmental Defense. [online] URL: $\underline{\text { http://labs.bio.unc.edu/ }}$ Peet/PEL/edbooklet.pdf

McGillivray, M., and F. Noorbakhsh. 2004. Composite indices of human well-being: past, present, and future. WIDER Research Paper 2004/63. UNU-WIDER, Helsinki, Finland.

National Oceanic and Atmospheric Administration (NOAA). 2000. Medium Shoreline. [online] URL: http://shoreline.noaa. gov/data/datasheets/medres.html (Accessed 15 May 2012).

Norman, L., Villarreal, M., Lara-Valencia, F., Yuan, Y., Nie, W., Wilson, S., Amaya, G., and R. Sleeter. Mapping socioenvironmentally vulnerable populations access and exposure to ecosystem services at the U.S.-Mexico borderlands. Applied Geography 34:413-424.

Oswald, A. J. and S. Wu. 2010. Objective confirmation of subjective measures of human well-being: Evidence from the USA. Science 327(5965):576-579. http://dx.doi.org/10.1126/ science. 1180606

Perrings, C. 2006. Ecological economics after the millennium assessment. International Journal of Ecological Economics and Statistics 6(F06):8-22.

Petrosillo, I., R. Costanza, R. Aretano, N. Saccarelli, and G. Zurlini. 2013. The use of subjective indicators to assess how natural and social capital support residents' quality of life in a small volcanic island. Ecological Indicators 24:609-620. http://dx. doi.org/10.1016/j.ecolind.2012.08.021

Scoones, I. 1998. Sustainable rural livelihoods: a framework for analysis. IDS Working Paper 72. Institute of Development Studies, University of Sussex, Brighton, UK.

Sen, A. 1999. Development as freedom. Oxford University Press, Oxford, UK. http://dx.doi.org/10.1017/CBO9780511808395.011

Smith, L., and J. K. Summers. 2011. Application of the human well-being index to tribal communities. National EPA-Tribal
Science Council (TSC) Fall 2011 Meeting (Catoosa, Oklahoma, USA, 2011) US Environmental Protection Agency, Washington, D.C., USA.

Summers, J. K. and L. Smith. 2010. The Relationships among Ecosystem Services and Human Well Being. A Community on Ecosystem Services 2010 (Gila River Indian Community, Arizona, USA, 2010) Institute of Food and Agricultural Sciences, University of Florida, Gainesville, Florida, USA.

Srinivasan, T. N. 1994. Human development: a new paradigm or reinvention of the wheel? The American Economic Review 84 (2):238-243.

The Nature Conservancy. 2009. TNC Lands. [online] URL: $\underline{\text { http:// }}$ maps.tnc.org/gis data.html\#TNClands

United Nations Development Programme (UNDP). 1990. Human development report 1990. United Nations Development Programme, New York, New York, USA. http://dx.doi. org/10.1057/9780230598508

United Nations Development Programme (UNDP). 2010. Human development index. United Nations Development Programme. [online] URL: http://hdr.undp.org/en/statistics/hdi/

United States Department of Agriculture (USDA), National Agricultural Statistics Service. 2009. Cropland Data Layer. Published crop-specific data layer. [online] URL: http:// nassgeodata.gmu.edu/CropScape USDA-NASS, Washington, DC (accessed 10 July 2010).

United States Geological Survey (USGS). 2006. National Hydrography Dataset - Flowline. [online] URL: http://www. horizon-systems.com/NHDPlus/NHDPlusV2 data.php (Accessed 10 July 2011)

Wilson, M. and R. B Howarth, Discourse-based valuation of ecosystem services: establishing fair outcomes through group deliberation. Ecological Economics 41(3):431-443. http://dx.doi. org/10.1016/S0921-8009(02)00092-7 


\section{Appendix 1: Additional Human Well-being Measures of Interest}

National gross domestic product per capita (GDP)

National gross domestic product per capita (GDP) is frequently used as an indicator or proxy for level of well-being. However, GDP is a simplistic measure and conveys little information beyond the size of the economy. In fact, increases in GDP potentially disguise declines in human and environmental conditions. From an environmental sustainability approach, Costanza and Daly (1992) explain that reductions in natural capital stocks, drawn down and transformed to increase economic output, are not accounted for in measuring GDP. Furthermore, Daly (2002) indicates that economic activity resulting from mitigation of the environmental and social harms of economic growth is reflected in further increasing GDP though these gains are the result of decreased well-being. Though economic conditions have an undisputable impact on quality of life, additional measures of are needed to more accurately represent HWB.

Index of Sustainable Economic Welfare Improving on GDP, the Index of Sustainable Economic Welfare (ISEW) includes the costs of defense expenditures, environmental degradation, and the depreciation of natural capital in addition to other more traditional economic growth measures (e.g., personal consumption). In its initial construction, the ISEW did not contain measures of social well-being or human health unless they influenced other economic factors. Like GDP, the ISEW and its successor the Genuine Progress Indicator were developed to be a national indicator of progress and not explicitly human well-being or quality of life.

Human Development Index

The Human Development Index (HDI), published annually since 1990 by the United Nations Development Programme, relies on national-level indicators of life expectancy at birth, literacy, and real GDP per capita to measure individuals' ability to lead a healthy life, be educated, and have access to resources for a decent standard of living (UNDP 1990). Indicators are equally weighted and countries are ranked by respective total scores. Criticisms of the HDI include inability to compare ratings across time periods, limited conceptualization of well-being, and data error (Klugman et al. 2011). The HDI's conceptualization of well-being is limited to only three dimensions, which is considered overly simplistic by some (Dasgupta and Weale 1992; Srinivasan 1994). It has also been argued that the HDI is a redundant tool, adding little to what is already known about measuring development because the indicators are closely correlated with each other and the composite HDI score (McGillivray 1991).

EPA Human Well-being Index

The U.S. Environmental Protection Agency developed and is applying the Human Well-being Index (HWBI) in tribal communities in the U.S. The index is geared towards public policy uses with the aim of providing communities and governing bodies with information and tools to increase community sustainability. The model, most recently described in Smith and Summers (2011), proposes environmental, societal, and economic elements of well-being, which can be evaluated through measurement within eight domains: social cohesion; education; connection to nature; health; living standards; leisure time; safety and security; and spiritual and cultural fulfillment. The HWBI incorporates subjectivity through including subjective indicators (e.g., level of biophelia and life satisfaction/happiness) and by weighting each indicator's contribution 
to overall well-being score based on its unique Relative Importance Value, which is a combination of public perception and professional opinion on the indicator's relative contribution to well-being (Summers and Smith 2010, Smith and Summers 2011). Little documentation exists on calculation of values for domains of wellbeing in the HWBI.

Federation of Canadian Municipalities' Quality of Life Reporting System

The Federation of Canadian Municipalities measures quality of life at a local level to address issues impacting residents in Canadian cities and municipalities. The Quality of Life Reporting System uses 11 dimensions: demographic and background information; affordable and appropriate housing; civic engagement; community and social infrastructure; education; employment; local economy; natural environment; personal and community health; personal financial security; and personal safety (Burrett 2009). These dimensions are measured using 72 indicators collected at the municipal level. The abundance of indicators presumably creates problems for data collection. Additionally, indicators overlap within and among well-being dimensions (e.g., local economy and employment) and some indicators may not contribute substantially to the conceptualization of well-being (e.g., rental housing starts and newspaper circulation). 
Appendix 2: Survey distributed to 2011 Albemarle-Pamlico meeting participants to adapt the Sustainable Livelihoods Framework to measure human well-being.

\section{Gauging Human Well-being in the Albemarle-Pamlico Basin}

Ecosystem services are inherently tied to human well-being, yet our definition of wellbeing is often vague or generalized. To more accurately assess trade-offs among ES and between ES and human well-being it is important to define human well-being in terms relevant to the Albemarle-Pamlico basin, but also transferable to other areas for comparison. In our efforts to characterize human well-being we have adopted a fiveprong framework that takes into account measures of human capital, financial capital, physical capital, social capital, and natural capital. This approach, also known as the Sustainable Livelihoods Framework, enables us to examine 1) trade-offs associated with changes in ecosystem service capacity and flow, 2) potential drivers of change, and 3) direct and indirect impacts on human well-being.

\section{Please take a moment to rate the following components of human well-being on a scale of 1-5, 5 being the most important component to your well-being.}

\begin{tabular}{lll}
\hline $\begin{array}{c}\text { Human Well- } \\
\text { being } \\
\text { Component }\end{array}$ & \multicolumn{1}{c}{ Definition } & Rating (1-5) \\
\hline Human capital & $\begin{array}{l}\text { The collection of knowledge, skills, and ability to } \\
\text { contribute to society (e.g. education, health, etc.) } \\
\text { Financial capital } \\
\text { Financial assets (e.g. money, stocks, etc.) that can be } \\
\text { used to purchase physical assets }\end{array}$ & \\
Physical capital & $\begin{array}{l}\text { Manufactured, non-human assets. Excludes raw } \\
\text { materials (e.g. house, boat, car) }\end{array}$ & \\
Social capital & $\begin{array}{l}\text { Social relations and networks that provide benefits; } \\
\text { can include formal and informal groups. }\end{array}$ & \\
Natural capital & $\begin{array}{l}\text { Stock of natural ecosystems that yields a flow of } \\
\text { ecosystem goods or services (e.g. trees, wetlands, } \\
\text { freshwater, etc.) }\end{array}$ & \\
\hline
\end{tabular}

In addition, there are different ways one could measure each component. Please take a moment to rate the following indicators/measures on a scale of 1-5, 5 being a very good indicator of this HWB component. Feel free to add additional indicators and their rating as needed on the next page. 
Human Well-Being Component and Indicators Rating (1-5)

\section{Human capital}

\begin{tabular}{l|l}
\hline Life expectancy & \\
\hline Infant mortality & \\
\hline \# of healthy days/person & \\
\hline Average commute time & \\
\hline Cancer rates/diabetes/chronic heart disease & \\
\hline Financial capital indicators & \\
\hline Income & \\
\hline Consumption & \\
\hline Cost of living & \\
\hline Investment in local businesses & \\
\hline Access to credit & \\
\hline Employment &
\end{tabular}

Physical capital indicators

Value of personal physical assets

Access to hospital and health care facilities

Infrastructure (roads per capita)

\begin{tabular}{l|l}
\hline Affordable housing & \\
\hline Affordable electricity & \\
\hline Public transportation options & \\
\hline Health insurance coverage & \\
\hline
\end{tabular}

\section{Social capital indicators}

\begin{tabular}{l|l}
\hline Recreation opportunities & \\
\hline $\begin{array}{l}\text { \# of and participation in religious or social } \\
\text { groups }\end{array}$ & \\
\hline Civic involvement (voting, meetings) & \\
\hline Education attainment & \\
\hline Divorce rate & \\
\hline $\begin{array}{l}\text { Participation in traditional } \\
\text { industries/occupations }\end{array}$ & \\
\hline Access to occupational tools & \\
\hline
\end{tabular}

Natural capital indicators

\begin{tabular}{l|l}
\hline Days inconvenienced by drought/flood & \\
\hline Access to green space or open land & \\
\hline Forest cover & \\
\hline Proximity to rivers or lakes & \\
\hline Abundance of fish and wildlife & \\
\hline
\end{tabular}


Appendix 3: Adapting the Sustainable Livelihoods Framework (SLF) for the AlbemarlePamlico Basin.

The original SLF equally weights and sums all capital asset indicators. The researchers chose to create partial weights for two indicators within each capital and for the capital assets contribution to overall HWB (equation 1). This equation reflects the contribution of each capital asset (financial, human, natural, physical, and social) to HWB and weights each capital indicator by dividing the mean (unscaled) rating by the sum of mean (unscaled) ratings (equation 2). This enabled assessment of the condition of each capital asset individually and collectively as a composite measure of HWB.

$$
\begin{gathered}
H W B=\sum_{i=\text { capitals }} X i\left(\left(x_{i 1} \times W x_{i 1}\right)+\left(x_{i 2} \times W x_{i 2}\right)\right) \\
W x_{i 1}=\frac{\text { rating } x_{i 1}}{\left(\text { rating } x_{i 1}+\text { rating } x_{i 1}\right)}
\end{gathered}
$$


Appendix 4: SLF indicator data selection

Indicator data were derived in tabular and spatial (ArcMap shapefiles) from a variety of sources (Table 3). Quantitative and mappable measures were found for most of the high-rated indicators, with the exception of religious or social group participation, access to health facilities, or abundance of fish and wildlife. For the first two, reliable county-level data did not extend through both states. The fish and wildlife abundance indicator was difficult to include at the Albemarle-Pamlico basin scale because there is no single provider of these data. The inclusion of many sources of data could potentially lead to wide uncertainty in the watershed scale assessment, so forested land and open space was used as a proxy.

Natural capital indicators were derived in ArcMap 10.0 (ESRI 2010) using the National Agriculture Statistical Survey cropland dataset (2009) for forest and open space cover, National Hydrography Data Plus (2006) for waterbody area and drainage density, and NOAA's medium resolution shoreline data (2000) for proximity to the ocean. Forest cover, open space, waterbody area, stream and river length, and shoreline length were summed for each county using a series of geoprocessing tools, including intersect with county boundary shapefile, summarize by attribute, and join summary results to county boundary data. Waterbody area, drainage density, and shoreline length were equally weighted and combined into a single indicator of proximity to water. Field calculator was used to rescale indicator values and created maps of all 10 indicators, five capital measures, and the composite HWB with and without weighting.

The researchers standardized county-level data for each indicator on a scale of 0 to 1 to compare among indicators (Equation 3). This allowed us to apply the aforementioned weighting equation (Equation 2) using the ranks assigned by workshop participants.

Scaled indicator value

$$
=\frac{\text { value observed }- \text { minimum observed value }}{\text { maximum value observed }- \text { minimum observed value }}
$$

